\title{
Using an Effective Numerical Method for Solving a Class of Lane-Emden Equations
}

\author{
Yulan Wang, ${ }^{1}$ Hao Yu, ${ }^{1}$ Fugui Tan, ${ }^{2}$ and Shuguang $\mathrm{Li}^{1}$ \\ ${ }^{1}$ Department of Mathematics, Inner Mongolia University of Technology, Hohhot 010051, China \\ ${ }^{2}$ Jining Teachers College, Wülánchábù, Inner Mongolia 012000, China \\ Correspondence should be addressed to Yulan Wang; wylnei@163.com
}

Received 26 March 2014; Revised 12 May 2014; Accepted 22 May 2014; Published 18 June 2014

Academic Editor: Igor Leite Freire

Copyright (c) 2014 Yulan Wang et al. This is an open access article distributed under the Creative Commons Attribution License, which permits unrestricted use, distribution, and reproduction in any medium, provided the original work is properly cited.

\begin{abstract}
We use the reproducing kernel method to solve the well-known classes of Lane-Emden-type equations. These classes of equations have the form of Lane-Emden problem. Comparing the results of the reproducing kernel method with the analytical solutions by means of some typical examples, we can affirm that the reproducing kernel method is an efficient and accurate method.
\end{abstract}

\section{Introduction}

Let us consider the following Lane-Emden problem:

$$
\begin{gathered}
u^{\prime \prime}(x)+\frac{n}{x} u^{\prime}(x)+f(u)=g(x), \quad x \in[0, b], \\
u(0)=\lambda_{1}, \quad u^{\prime}(0)=\lambda_{2},
\end{gathered}
$$

where $n \geq 0, g(x)$ is given bounded, continuous function, and $f(u)$ is nonlinear function; in [1], we can see that the most popular form of $f(u)$ is $f(u)=u^{m}$, where $m$ is a constant parameter; this type of equation is the Lane-Emden equations of the first kind; in addition, $f(u)$ can be the exponential functions $f(u)=e^{u}$; this type of equations is called the Lane-Emden equations of the second kind; furthermore, the function $f(u)$ can be logarithmic functions and trigonometric functions; all these types of equations are named after the astrophysicists Jonathan Lane and Robert Emden; they were the first to study these types of equations. Lane-Emden equations are widely used in various physical phenomena. Many scholars [2-5] devote their energies to this field, with the high development of computer technology; lots of numerical methods have been put forward to solve this type of equation, such as pseudospectral method, Haar wavelet method, and Adomian decomposition method (ADM) [6-11].

Reproducing kernel method (RKM) is an attractive method because of its accuracy, and it has already been applied to various fields. In this paper, we use the reproducing kernel method to solve (1) to show the efficiency and accuracy of this method.

\section{The Reproducing Kernel Method}

2.1. Practise Homogenization for Lane-Emden Equations. In order to use reproducing kernel method to solve (1), we need to practise homogenization for (1); previously, we multiplied (1) by $x$; we find that

$$
\begin{gathered}
(\mathscr{L} u)(x)=F(x, u), \quad x \in[0, b], \\
u(0)=\lambda_{1}, \quad u^{\prime}(0)=\lambda_{2},
\end{gathered}
$$

where $\mathscr{L} u(x)=x u^{\prime \prime}(x)+n u^{\prime}(x), F(x, u)=x g(x)-x f(u)$. Obviously, the solution of (2) is the solution of (1). So we only need to gain the solution of (2). The question (2) with nonhomogeneous boundary value conditions is equivalent to the problem of having a function $v(x)$ satisfying

$$
\begin{aligned}
(\mathscr{L} v)(x) & =\bar{F}(x, v), \quad x \in[0, b], \\
v(0) & =0, \quad v^{\prime}(0)=0,
\end{aligned}
$$

where $\bar{F}(x, v)=x g(x)-x f\left(v+\lambda_{1}+\lambda_{2} x\right)-\lambda_{2} n$.

2.2. Construct Reproducing Kernel Space. Aiming at the purpose of solving (3), we need to introduce the reproducing 

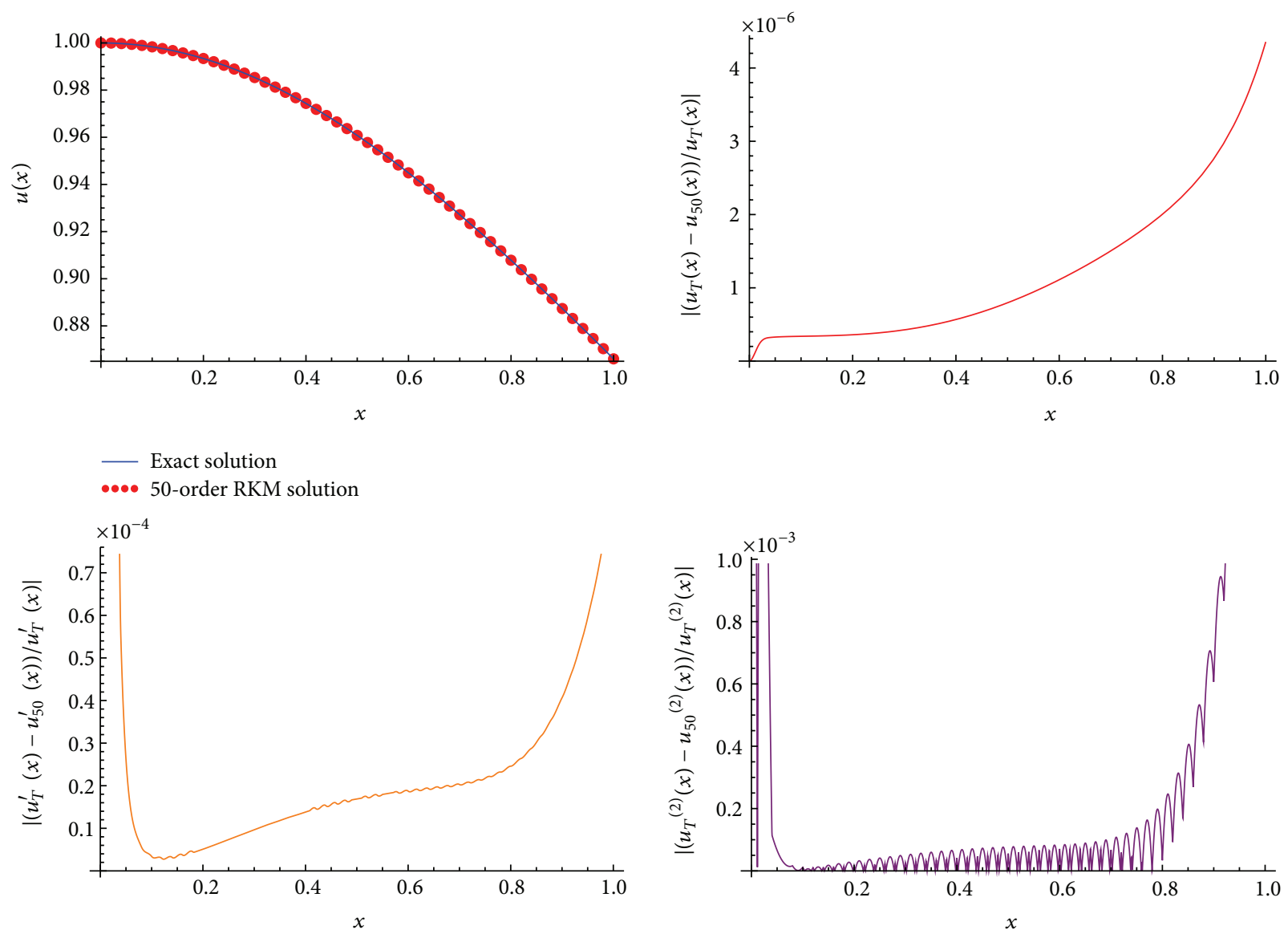

FIgURE 1: Present numerical method for Example 1.

kernel space; previously, let us introduce the concept of the reproducing kernel space.

For each of $x \in X$, there is a function of two variables $K_{x}(y) \in H$, where $H$ is Hilbert space and $X$ is a set abstraction. If we can get

$$
\left\langle u(y), K_{x}(y)\right\rangle=u(x), \quad u(y) \in H,
$$

we say that $H$ is the reproducing kernel Hilbert space and $K_{x}(y)$ is the reproducing kernel of $H$.

We give a linear space $W_{2}^{3}[0, b]$ as follows:

$$
\begin{aligned}
W_{2}^{3}[0, b] & \\
& =\left\{u \mid u, u^{\prime}, u^{\prime \prime}\right.
\end{aligned}
$$

is one-variable absolutely continuous function,

$$
\left.u^{\prime \prime \prime} \in L^{2}[0, b], u(0)=0, u^{\prime}(0)=0\right\} .
$$

According to $[12,13]$, we give the inner product as follows:

$$
\langle u(y), v(y)\rangle=u^{\prime \prime}(0) v^{\prime \prime}(0)+\int_{0}^{b} u^{\prime \prime \prime}(y) v^{\prime \prime \prime}(y) d y .
$$

And according to [14], we can prove that $W_{2}^{3}[0, b]$ is a reproducing kernel space; its reproducing kernel $R(x, y)$ is

$$
\begin{aligned}
& R(x, y) \\
& \quad=\left\{\begin{array}{cc}
\frac{1}{120}\left(120+x^{5}+120 x y\right. & \\
\left.-5 x^{4} y+30 x^{2} y^{2}+10 x^{3} y^{2}\right), & x<y, \\
\frac{1}{120}\left(120+y^{5}+10 x^{2} y^{2}(3+y)\right. & \\
\left.-5 x y\left(y^{3}-24\right)\right), & y<x .
\end{array}\right.
\end{aligned}
$$

In order to use reproducing kernel method to solve (3) and referring to $[15,16]$, we can get $\psi_{i}(x)$ as follows:

$$
\begin{aligned}
& \psi_{i}(x) \\
& =\left\{\begin{array}{cc}
\left(\frac{1}{24} x(4 x(3+x) y\right. & \\
\left.\left.+n\left(24-x^{3}+12 x y+4 x^{2} y\right)\right)\right)\left.\right|_{y=x_{i}}, & x<y, \\
\left(\frac { 1 } { 2 4 } \left(4 y\left(-3 x y^{2}+y^{3}+3 x^{2}(1+y)\right)\right.\right. & \\
+n\left(y^{4}+6 x^{2} y(2+y)\right. & \\
\left.\left.\left.-4 x\left(-6+y^{3}\right)\right)\right)\right)\left.\right|_{y=x_{i}} & y<x,
\end{array}\right.
\end{aligned}
$$

where $i=1,2,3, \ldots$ 

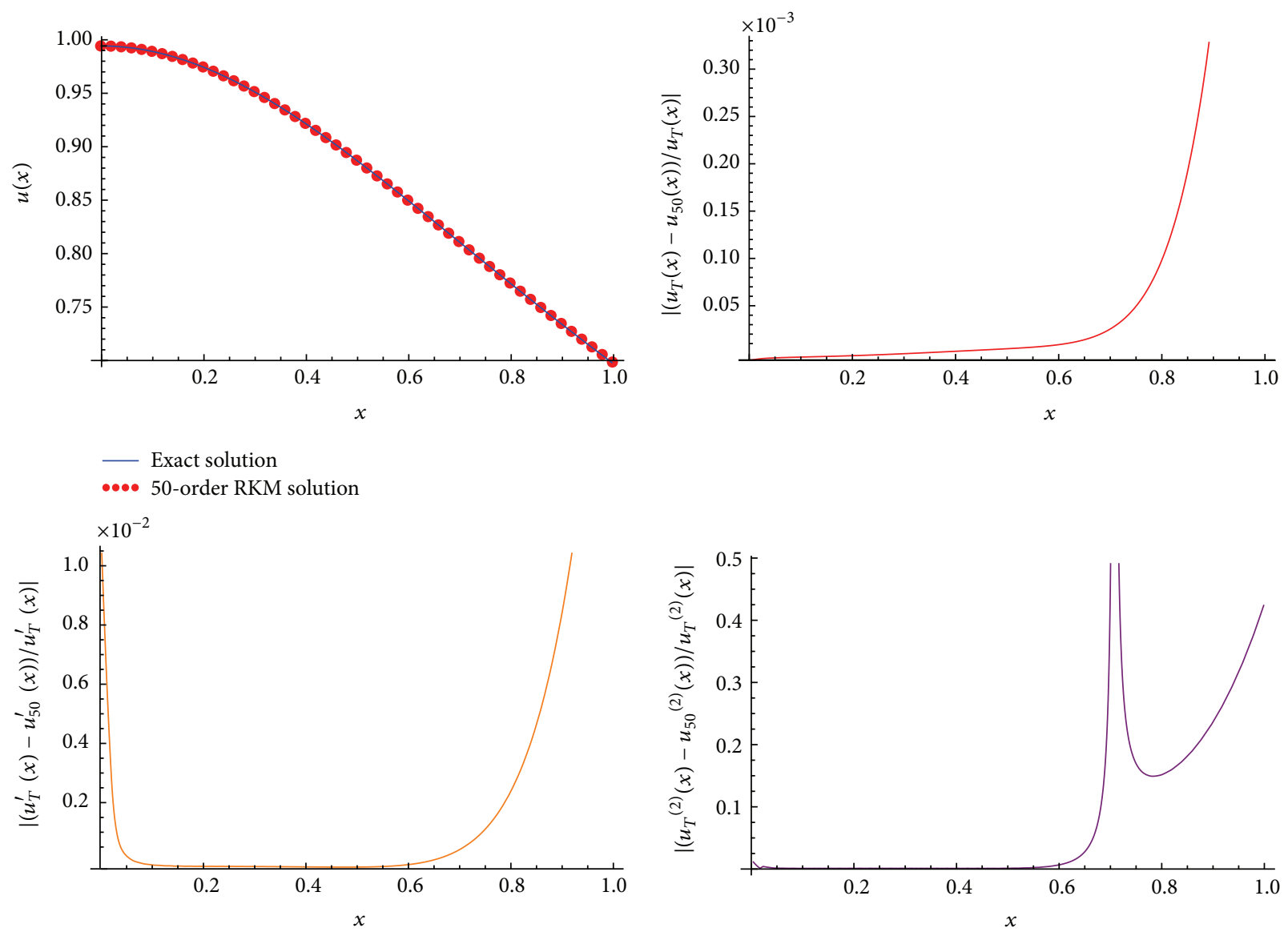

FIGURE 2: Present numerical method for Example 2.

TABLE 1: Numerical solutions for Example 1.

\begin{tabular}{|c|c|c|c|c|c|}
\hline$x$ & $u_{T}(x)$ & $u_{50}$ & $\left|u_{T}(x)-u_{50}(x)\right|$ & $\left|u_{T}^{\prime}(x)-u_{50}^{\prime}(x)\right|$ & $\left|u_{T}^{\prime \prime}(x)-u_{50}^{\prime \prime}(x)\right|$ \\
\hline 0.0 & 1 & 1 & 0 & 0 & 0.00298864 \\
\hline 0.1 & 0.998337 & 0.998338 & $3.37916 \times 10^{-7}$ & $1.12915 \times 10^{-7}$ & $3.93668 \times 10^{-6}$ \\
\hline 0.2 & 0.993399 & 0.9934 & $3.57116 \times 10^{-7}$ & $3.49412 \times 10^{-7}$ & $5.2331 \times 10^{-6}$ \\
\hline 0.3 & 0.985329 & 0.98533 & $4.20119 \times 10^{-7}$ & $9.49753 \times 10^{-7}$ & $8.31208 \times 10^{-6}$ \\
\hline 0.4 & 0.974355 & 0.974355 & $5.53188 \times 10^{-7}$ & $1.72224 \times 10^{-6}$ & $1.10979 \times 10^{-5}$ \\
\hline 0.5 & 0.960769 & 0.96077 & $7.64858 \times 10^{-7}$ & $2.49738 \times 10^{-6}$ & $1.31351 \times 10^{-5}$ \\
\hline 0.6 & 0.944911 & 0.944912 & $1.04891 \times 10^{-6}$ & $3.16098 \times 10^{-6}$ & $1.37757 \times 10^{-5}$ \\
\hline 0.7 & 0.927146 & 0.927147 & $1.39484 \times 10^{-6}$ & $3.77284 \times 10^{-6}$ & $1.06634 \times 10^{-5}$ \\
\hline 0.8 & 0.907841 & 0.907843 & $1.81934 \times 10^{-6}$ & $4.9052 \times 10^{-6}$ & $3.95915 \times 10^{-6}$ \\
\hline 0.9 & 0.887357 & 0.887359 & $2.455 \times 10^{-6}$ & $8.51793 \times 10^{-6}$ & $5.08462 \times 10^{-5}$ \\
\hline 1.0 & 0.866025 & 0.866029 & $3.77266 \times 10^{-6}$ & $1.98432 \times 10^{-5}$ & $1.76573 \times 10^{-4}$ \\
\hline
\end{tabular}

Then practise Gram-Schmidt orthonormalization for $\left\{\psi_{i}(x)\right\}_{i=1}^{\infty}$; according to $[17,18]$ we get

$$
\begin{aligned}
\bar{\psi}_{1}(x) & =\beta_{11} \psi_{1}(x), \\
\bar{\psi}_{2}(x) & =\beta_{21} \psi_{1}(x)+\beta_{22} \psi_{2}(x), \\
\bar{\psi}_{3}(x) & =\beta_{31} \psi_{1}(x)+\beta_{32} \psi_{2}(x)+\beta_{33} \psi_{3}(x), \\
& \vdots \\
\bar{\psi}_{i}(x) & =\beta_{i 1} \psi_{1}(x)+\beta_{i 2} \psi_{2}(x)+\beta_{i 3} \psi_{3}(x)+\cdots+\beta_{i i} \psi_{i}(x),
\end{aligned}
$$

where $\beta_{i k}$ are coefficients of Gram-Schmidt orthonormalization.

If $\left\{x_{i}\right\}_{i=1}^{\infty}$ are distinct points dense in $[0, b]$ and $\mathscr{L}^{-1}$ is existent, we get that

$$
u(x)=\sum_{i=1}^{\infty} \sum_{k=1}^{i} \beta_{i k} \bar{F}\left(x_{k}, v\left(x_{k}\right)\right) \bar{\psi}_{i}(x)+\lambda_{1}+\lambda_{2} x
$$

is the solution of (3). The proof of it refers to $[19,20]$. If the equations are linear ones, $\bar{F}(x, v)=\bar{F}(x)$, we can solve the problems directly. If they are nonlinear equations, we have to use iteration method to solve them, and the specific methodology refers to $[21,22]$. 

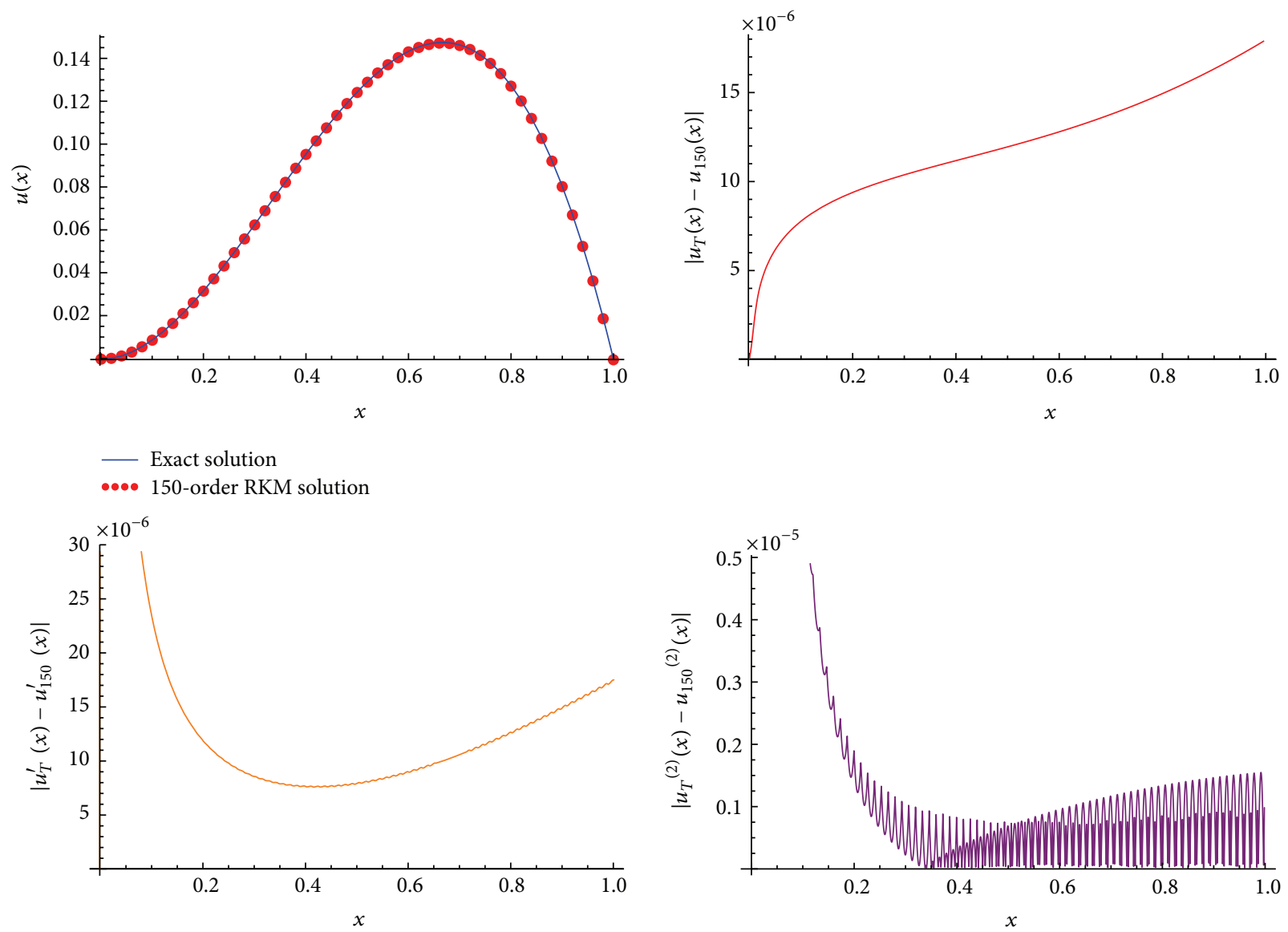

FIgURE 3: Present numerical method for Example 3.

TABle 2: Numerical solutions for Example 2.

\begin{tabular}{lccccc}
\hline$x$ & $u_{T}(x)$ & $u_{50}$ & $\left|u_{T}(x)-u_{50}(x)\right|$ & $\left|u_{T}^{\prime}(x)-u_{50}^{\prime}(x)\right|$ & 0 \\
\hline 0.0 & 1 & 1 & 0 & $1 u_{T}^{\prime \prime}(x)-u_{50}^{\prime \prime}(x) \mid$ \\
0.1 & 0.995037 & 0.99504 & $2.93318 \times 10^{-6}$ & $1.29666 \times 10^{-5}$ & 1.0112026 \\
0.2 & 0.980581 & 0.980585 & $4.30454 \times 10^{-6}$ & $1.58583 \times 10^{-5}$ & $1.26869 \times 10^{-4}$ \\
0.3 & 0.957826 & 0.957832 & $6.15161 \times 10^{-6}$ & $2.06044 \times 10^{-5}$ & $1.3056 \times 10^{-4}$ \\
0.4 & 0.928477 & 0.928485 & $8.27303 \times 10^{-6}$ & $2.10852 \times 10^{-5}$ & $1.15115 \times 10^{-4}$ \\
0.5 & 0.894427 & 0.894438 & $1.03314 \times 10^{-6}$ & $2.12716 \times 10^{-5}$ & $1.93154 \times 10^{-5}$ \\
0.6 & 0.857493 & 0.857506 & $1.34827 \times 10^{-5}$ & $5.30101 \times 10^{-5}$ & $7.5356 \times 10^{-4}$ \\
0.7 & 0.819232 & 0.819258 & $2.59653 \times 10^{-5}$ & $2.43656 \times 10^{-4}$ & $3.6414 \times 10^{-3}$ \\
0.8 & 0.780869 & 0.780948 & $7.95391 \times 10^{-5}$ & $9.70462 \times 10^{-4}$ & $1.22923 \times 10^{-2}$ \\
0.9 & 0.743294 & 0.74356 & $2.66219 \times 10^{-4}$ & $3.10842 \times 10^{-3}$ & $3.31332 \times 10^{-2}$ \\
1.0 & 0.707107 & 0.707909 & $8.02319 \times 10^{-4}$ & & $8.31259 \times 10^{-3}$ \\
\hline
\end{tabular}

2.3. The Approximate Solution. We denote the approximate solution of $u_{m}(x)$ by

$$
u_{m}(x)=\sum_{i=1}^{m} \sum_{k=1}^{i} \beta_{i k} \bar{F}\left(x_{k}, v\left(x_{k}\right)\right) \bar{\psi}_{i}(x)+\lambda_{1}+\lambda_{2} x
$$

According to the proof of [23] we can easily get that $\| u_{m}(x)-$ $u(x) \| \rightarrow 0$ and $u_{m}^{(k)}(x) \rightarrow u^{(k)}(x), k=0,1,2$.

\section{Numerical Experiment}

Example 1. Let us talk about the well-known polytropic differential equation in [3]. Consider

$$
\begin{gathered}
u^{\prime \prime}+\frac{2}{x} u^{\prime}+u^{5}(x)=0, \quad x \in[0,1], \\
u(0)=1, \quad u^{\prime}(0)=0,
\end{gathered}
$$



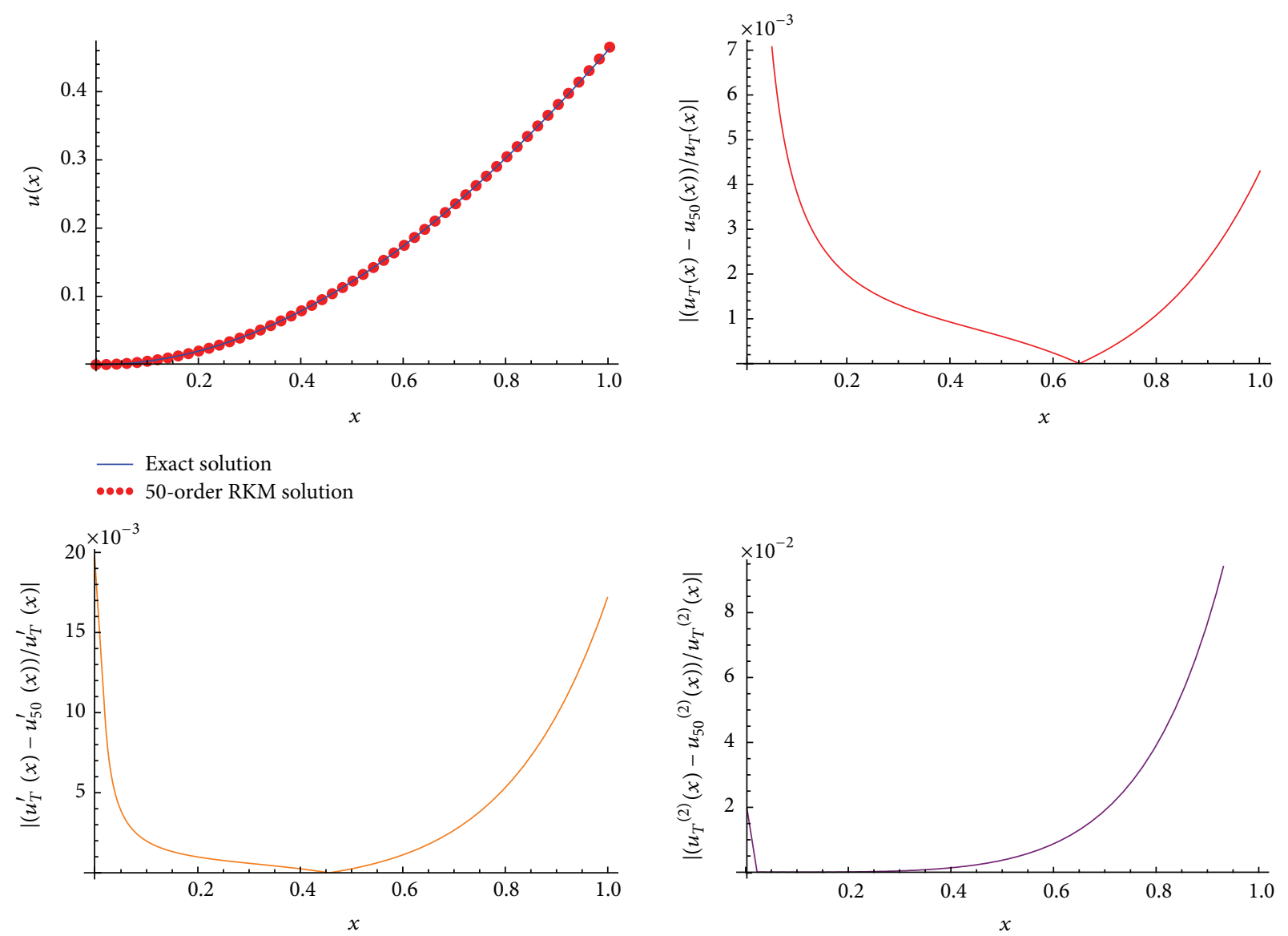

FIGURE 4: Present numerical method for Example 4.

TABLE 3: Numerical solutions for Example 3.

\begin{tabular}{|c|c|c|c|c|}
\hline$x$ & $\begin{array}{c}\text { Exact solution } \\
u_{T}(x)\end{array}$ & $\begin{array}{l}\text { 50-order RKM approximation } \\
\qquad u_{50}(x)\end{array}$ & $\begin{array}{c}100 \text {-order RKM approximation } \\
u_{100}(x)\end{array}$ & $\begin{array}{c}\text { 150-order RKM approximation } \\
u_{150}(x) \\
\end{array}$ \\
\hline 0.0 & 0 & 0 & 0 & 0 \\
\hline 0.1 & 0.009 & 0.00886466 & 0.00897728 & 0.00899228 \\
\hline 0.2 & 0.032 & 0.0318207 & 0.0319718 & 0.0319906 \\
\hline 0.3 & 0.063 & 0.0627957 & 0.0629686 & 0.0629896 \\
\hline 0.4 & 0.096 & 0.0957782 & 0.0959661 & 0.0959888 \\
\hline 0.5 & 0.125 & 0.124764 & 0.124964 & 0.124988 \\
\hline 0.6 & 0.144 & 0.143752 & 0.143962 & 0.143987 \\
\hline 0.7 & 0.147 & 0.146741 & 0.14696 & 0.146986 \\
\hline 0.8 & 0.128 & 0.12773 & 0.127957 & 0.127985 \\
\hline 0.9 & 0.081 & 0.0807176 & 0.0809539 & 0.0809837 \\
\hline 1.0 & 0 & -0.000295352 & -0.0000496372 & -0.0000179019 \\
\hline
\end{tabular}

whose exact solution is given by $u_{T}(x)=\left(1+x^{2} / 3\right)^{-1 / 2}$; using the reproducing kernel method, $x_{i}=i h, h=1 / N$, $i=1,2, \ldots, N$, and $N=50$. The numerical results are shown in Figure 1 and Table 1.

Example 2. Considering the following nonlinear equation:

$$
\begin{gathered}
u^{\prime \prime}(x)+\frac{1}{x} u^{\prime}(x)-u^{3}(x)+3 u^{5}(x)=0, \quad x \in[0,1] \\
u(0)=1, \quad u^{\prime}(0)=0,
\end{gathered}
$$

the exact solution is given by $u_{T}(x)=1 / \sqrt{1+x^{2}}$; using the reproducing kernel method, $x_{i}=i h, h=1 / N, i=1,2, \ldots, N$, and $N=50$. The numerical results are shown in Figure 2 and Table 2.

Example 3. Consider a linear Lane-Emden equation:

$$
u^{\prime \prime}(x)+\frac{1}{x} u^{\prime}(x)+u(x)=g(x), \quad x \in[0,1],
$$



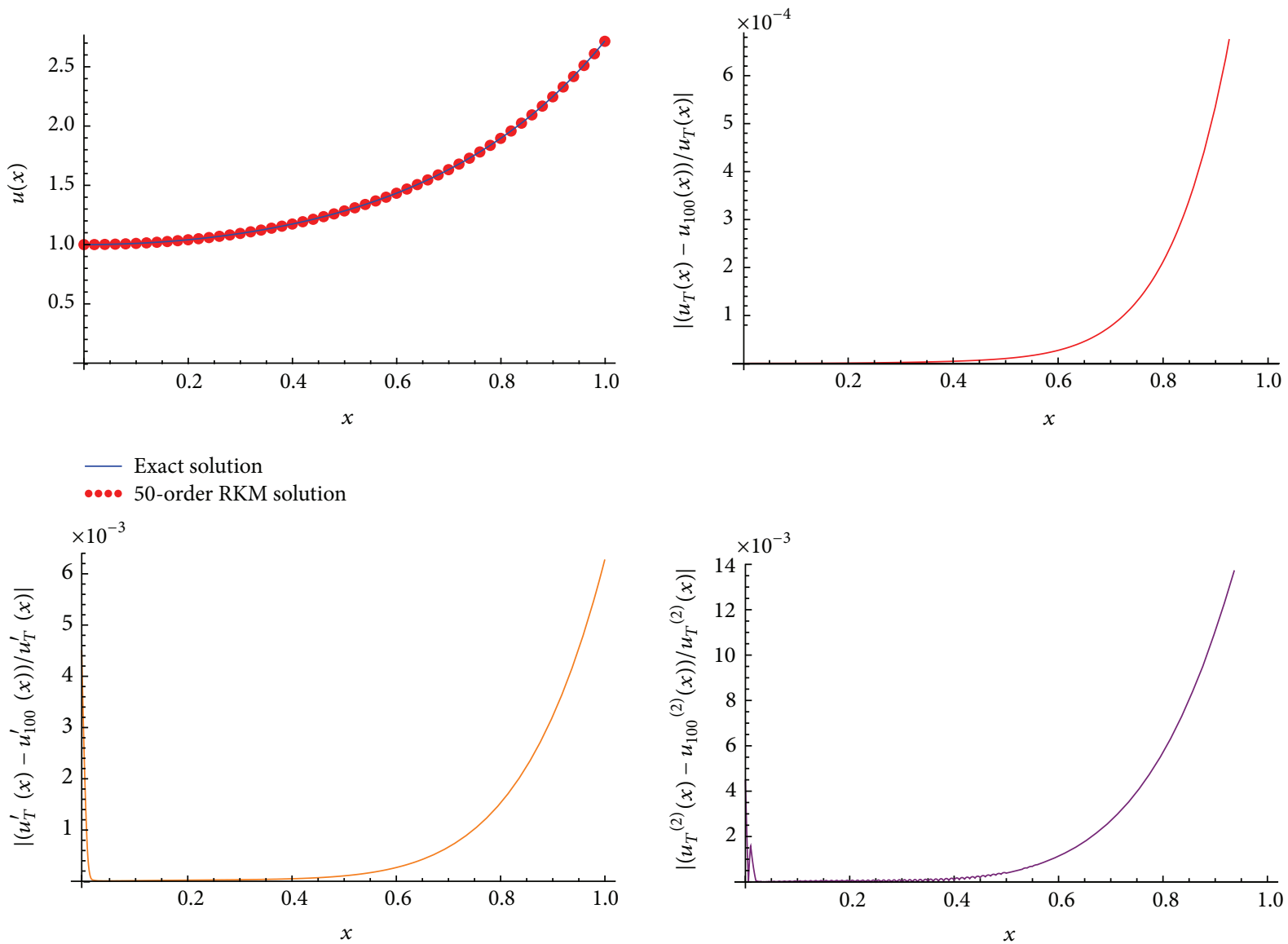

FIGURE 5: Present numerical method for Example 5.

where $g(x)=4-9 x+x^{2}-x^{3}$; using the reproducing kernel method, $x_{i}=i h, h=1 / N, i=1,2, \ldots, N$, and $N=$ $50,100,150$. The exact solution is given by $u_{T}(x)=x^{2}-x^{3}$. The numerical results are presented in Figure 3 and Table 3.

Example 4. Consider a Lane-Emden equation of the second kind in [1]. One has

$$
\begin{gathered}
u^{\prime \prime}(x)+\frac{n}{x} u^{\prime}(x)+e^{u(x)}=0, \quad n \geq 0, \\
u(0)=0, \quad u^{\prime}(0)=0,
\end{gathered}
$$

where $n=0$; using the reproducing kernel method, $x_{i}=i h$, $h=1 / N, i=1,2, \ldots, N$, and $N=50$. The exact solution is given by $u_{T}(x)=2 \operatorname{Ln}(\operatorname{sech}(x / \sqrt{2}))$. The numerical results are presented in Figure 4 and Table 4.

Example 5. Consider a Lane-Emden equation in [3]. One has

$$
\begin{gathered}
u^{\prime \prime}(x)+\frac{2}{x} u^{\prime}(x)+4\left(2 e^{u(x)}+e^{u(x) / 2}\right)=0, \quad x \geq 0, \\
u(0)=0, \quad u^{\prime}(0)=0 .
\end{gathered}
$$

Using the reproducing kernel method, $x_{i}=i h, h=1 / N$, $i=1,2, \ldots, N$, and $N=50$. The exact solution is given by
$u_{T}(x)=-2 \operatorname{Ln}\left(1+x^{2}\right)$. The numerical results are presented in Figure 5 and Table 5.

\section{Conclusions and Remarks}

In this paper, reproducing kernel method has been used to solve some typical Lane-Emden examples; the computation implies that the solutions by the reproducing kernel method are very accurate. Moreover, the first and second derivatives of the solutions also have very high accuracy. From all of this, we can affirm that the reproducing kernel method is an efficient and accurate method. All computations are performed by the Mathematica 8.0 software package.

\section{Conflict of Interests}

The authors declare that there is no conflict of interests regarding the publication of this paper.

\section{Acknowledgments}

The authors thank the reviewers for their valuable suggestions, which greatly improved the quality of the paper. This paper is supported by the Natural Science Foundation of 
TABLE 4: Numerical solutions for Example 4.

\begin{tabular}{lccccc}
\hline$x$ & $u_{T}(x)$ & $u_{50}$ & $\left|u_{T}(x)-u_{50}(x)\right|$ & $\left|u_{T}^{\prime}(x)-u_{50}^{\prime}(x)\right|$ & 0 \\
\hline 0.0 & 0 & 0 & 0 & $\left|u_{T}^{\prime \prime}(x)-u_{50}^{\prime \prime}(x)\right|$ \\
0.1 & 0.00499584 & 0.00497722 & $1.86175 \times 10^{-5}$ & $2.00342 \times 10^{-4}$ & 0.0198013 \\
0.2 & 0.0199337 & 0.0198951 & $3.85998 \times 10^{-5}$ & $1.97876 \times 10^{-4}$ & $2.32373 \times 10^{-5}$ \\
0.3 & 0.0446665 & 0.0446089 & $5.76023 \times 10^{-5}$ & $1.76911 \times 10^{-4}$ & $4.09236 \times 10^{-4}$ \\
0.4 & 0.0789556 & 0.0788834 & $7.21411 \times 10^{-5}$ & $9.9302 \times 10^{-5}$ & $1.3039 \times 10^{-3}$ \\
0.5 & 0.122479 & 0.122407 & $7.29154 \times 10^{-5}$ & $1.17118 \times 10^{-4}$ & $3.30994 \times 10^{-3}$ \\
0.6 & 0.174846 & 0.174807 & $3.90139 \times 10^{-5}$ & $6.28561 \times 10^{-4}$ & $7.38437 \times 10^{-3}$ \\
0.7 & 0.235604 & 0.235676 & $7.16611 \times 10^{-5}$ & $1.71224 \times 10^{-3}$ & $1.50496 \times 10^{-2}$ \\
0.8 & 0.304261 & 0.304599 & $3.37896 \times 10^{-4}$ & $3.83982 \times 10^{-3}$ & $2.87368 \times 10^{-2}$ \\
0.9 & 0.380294 & 0.381194 & $8.99901 \times 10^{-4}$ & $7.7914 \times 10^{-3}$ & $5.2279 \times 10^{-2}$ \\
1.0 & 0.463163 & 0.465161 & $1.99826 \times 10^{-3}$ & $1.48297 \times 10^{-2}$ & $9.16336 \times 10^{-2}$ \\
\hline
\end{tabular}

TABLE 5: Numerical solutions for Example 5.

\begin{tabular}{lccc}
\hline$x$ & Exact solution & 50-order RKM approximation & \multicolumn{2}{c}{ The approximation solutions in [3] } \\
& $u_{T}(x)$ & $u_{50}(x)$ & 0 \\
\hline 0.0 & 0 & 0 & -0.0001970587 \\
0.01 & -0.0001999900 & -0.00019999 & -0.0198967225 \\
0.1 & -0.0199006617 & -0.0199007 & -0.4462840851 \\
0.5 & -0.4462871026 & -0.446287 & -1.3862934297 \\
1.0 & -1.3862943611 & -1.38629 & -3.2188763248 \\
2.0 & -3.2188758249 & -3.21888 & -4.6051709964 \\
3.0 & -4.6051701860 & -4.60517 & -5.6664274573 \\
4.0 & -5.6664266881 & -5.66643 & \\
\hline
\end{tabular}

China (no. 11361037), the Natural Science Foundation of Inner Mongolia (no. 2013MS0109), and Project Application Technology Research and Development Foundation of Inner Mongolia (no. 20120312).

\section{References}

[1] A.-M. Wazwaz, R. Rach, and J.-S. Duan, "Adomian decomposition method for solving the Volterra integral form of the LaneEmden equations with initial values and boundary conditions," Applied Mathematics and Computation, vol. 219, no. 10, pp. 5004-5019, 2013.

[2] M. Dehghan, S. Aryanmehr, and M. R. Eslahchi, "A technique for the numerical solution of initial-value problems based on a class of Birkhoff-type interpolation method," Journal of Computational and Applied Mathematics, vol. 244, pp. 125-139, 2013.

[3] K. Parand, M. Dehghan, A. R. Rezaei, and S. M. Ghaderi, "An approximation algorithm for the solution of the nonlinear LaneEmden type equations arising in astrophysics using Hermite functions collocation method," Computer Physics Communications, vol. 181, no. 6, pp. 1096-1108, 2010.

[4] C. Harley and E. Momoniat, "Instability of invariant boundary conditions of a generalized Lane-Emden equation of the second-kind," Applied Mathematics and Computation, vol. 198, no. 2, pp. 621-633, 2008.

[5] E. Momoniat and C. Harley, "An implicit series solution for a boundary value problem modelling a thermal explosion," Mathematical and Computer Modelling, vol. 53, no. 1-2, pp. 249-260, 2011.

[6] A.-M. Wazwaz, "The combined Laplace transform-Adomian decomposition method for handling nonlinear Volterra integro-differential equations," Applied Mathematics and Computation, vol. 216, no. 4, pp. 1304-1309, 2010.
[7] J.-S. Duan, R. Rach, A.-M. Wazwaz, T. Chaolu, and Z. Wang, "A new modified Adomian decomposition method and its multistage form for solving nonlinear boundary value problems with Robin boundary conditions," Applied Mathematical Modelling, vol. 37, no. 20-21, pp. 8687-8708, 2013.

[8] J. S. Duan, R. Rach, and A. Wazwaz, "Solution of the model of beam-type micro- and nano-scale electrostatic actuators by a new modified Adomian decomposition method for nonlinear boundary value problems," International Journal of Non-Linear Mechanics, vol. 49, pp. 159-169, 2013.

[9] M. M. Al-Sawalha, M. S. M. Noorani, and I. Hashim, "Numerical experiments on the hyperchaotic Chen system by the Adomian decomposition method," International Journal of Computational Methods, vol. 5, no. 3, pp. 403-412, 2008.

[10] S. Ghosh, A. Roy, and D. Roy, "An adaptation of Adomian decomposition for numeric-analytic integration of strongly nonlinear and chaotic oscillators," Computer Methods in Applied Mechanics and Engineering, vol. 196, no. 4-6, pp. 1133-1153, 2007.

[11] A. Y. Al Bayati, A. J. AL Sawoor, and M. A. Samarji, "A multistage Adomian decomposition method for solving the autonomous Van Der Pol system," Australian Journal of Basic and Applied Sciences, vol. 3, no. 4, pp. 4397-4407, 2009.

[12] Y. L. Wang, X. J. Cao, and X. Li, "A new method for solving singular fourth-order boundary value problems with mixed boundary conditions," Applied Mathematics and Computation, vol. 217, no. 18, pp. 7385-7390, 2011.

[13] Y. L. Wang, M. J. Du, F. Tan, Z. Li, and T. Nie, "Using reproducing kernel for solving a class of fractional partial differential equation with non-classical conditions," Applied Mathematics and Computation, vol. 219, no. 11, pp. 5918-5925, 2013.

[14] Z. Li, Y. Wang, F. Tan, X. Wan, and T. Nie, "The solution of a class of singularly perturbed two-point boundary value problems by 
the iterative reproducing kernel method," Abstract and Applied Analysis, vol. 2012, Article ID 984057, 7 pages, 2012.

[15] Y. L. Wang, S. Lu, F. Tan, M. Du, and H. Yu, "Solving a class of singular fifth-order boundary value problems using reproducing kernel Hilbert space method," Abstract and Applied Analysis, vol. 2013, Article ID 925192, 6 pages, 2013.

[16] Z. Y. Li, Y. L. Wang, and F. Tan, "The solution of a class of thirdorder boundary value problems by the reproducing kernel method," Abstract and Applied Analysis, vol. 2012, Article ID 195310, 11 pages, 2012.

[17] X. Y. Li, B. Y. Wu, and R. T. Wang, "Reproducing kernel method for fractional riccati differential equations," Abstract and Applied Analysis, vol. 2014, Article ID 970967, 6 pages, 2014.

[18] F. Z. Geng and S. P. Qian, "Solving singularly perturbed multipantograph delay equations based on the reproducing kernel method," Abstract and Applied Analysis, vol. 2014, Article ID 794716, 6 pages, 2014.

[19] L.-H. Yang, H.-Y. Li, and J.-R. Wang, "Solving a system of linear Volterra integral equations using the modified reproducing kernel method," Abstract and Applied Analysis, vol. 2013, Article ID 196308, 5 pages, 2013.

[20] L. H. Yang and M. G. Cui, "New algorithm for a class of nonlinear integro-differential equations in the reproducing kernel space," Applied Mathematics and Computation, vol. 174, no. 2, pp. 942-960, 2006.

[21] X. Q. Lv and M. G. Cui, "An efficient computational method for linear fifth-order two-point boundary value problems," Journal of Computational and Applied Mathematics, vol. 234, no. 5, pp. 1551-1558, 2010.

[22] M. G. Cui and Z. Chen, "The exact solution of nonlinear agestructured population model," Nonlinear Analysis: Real World Applications, vol. 8, no. 4, pp. 1096-1112, 2007.

[23] J. N. Niu, Y. Z. Lin, and M. G. Cui, "A novel approach to calculation of reproducing kernel on infinite interval and applications to boundary value problems," Abstract and Applied Analysis, vol. 2013, Article ID 959346, 7 pages, 2013. 


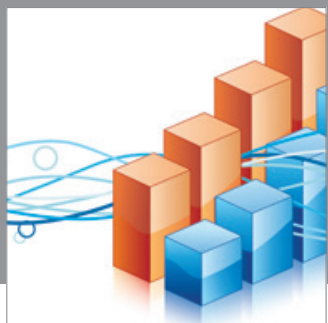

Advances in

Operations Research

mansans

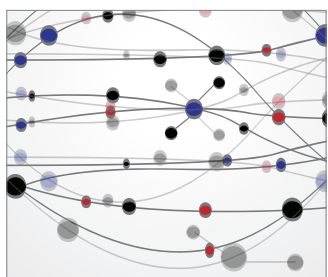

The Scientific World Journal
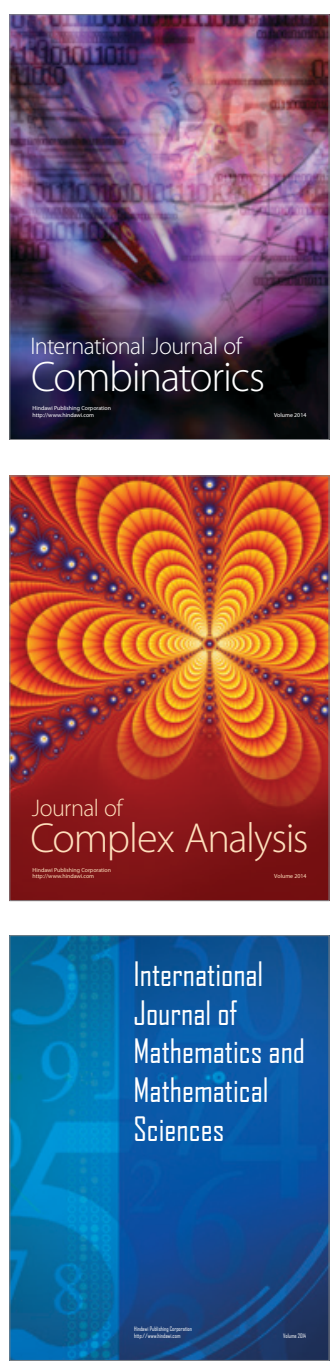
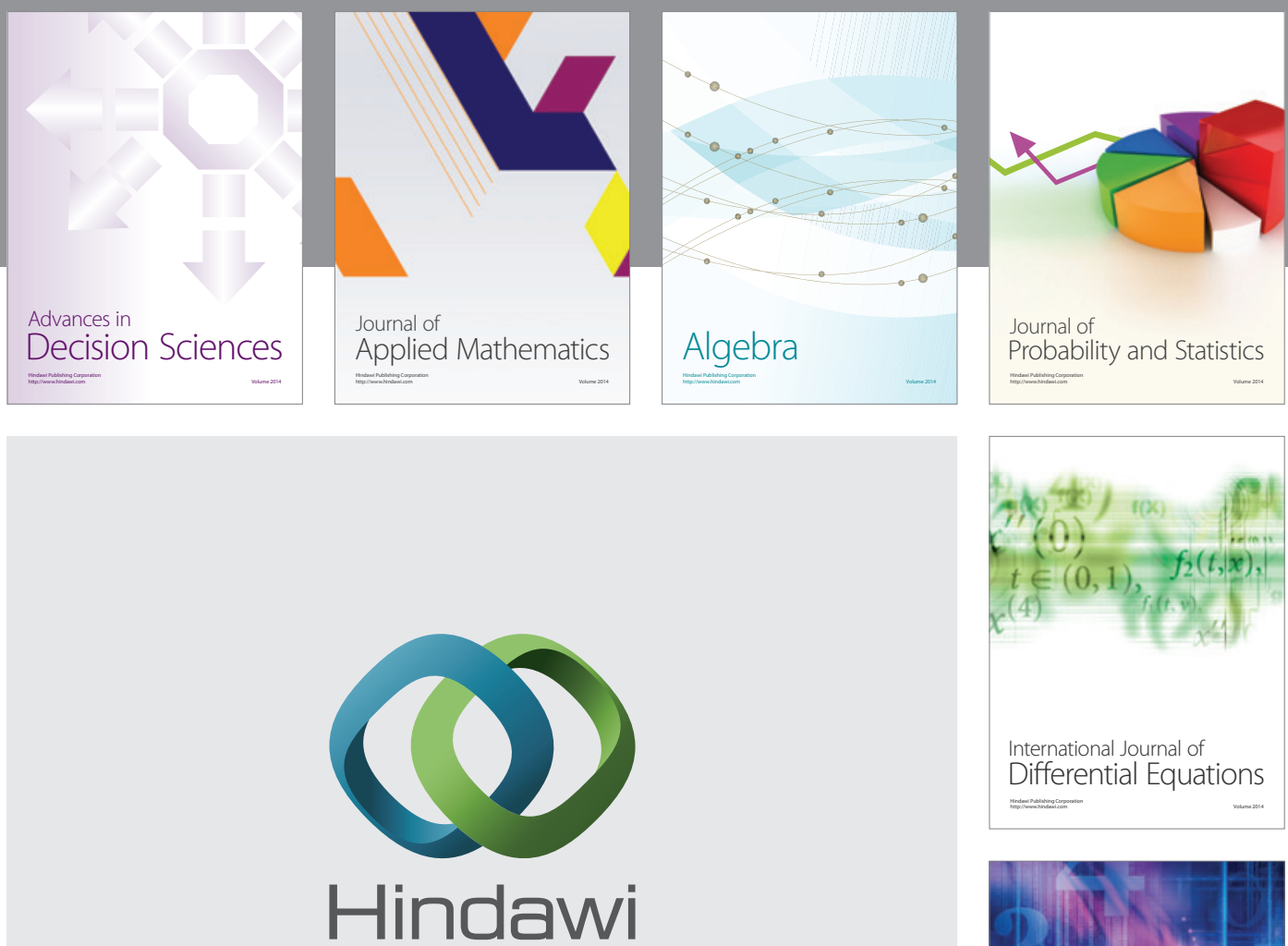

Submit your manuscripts at http://www.hindawi.com
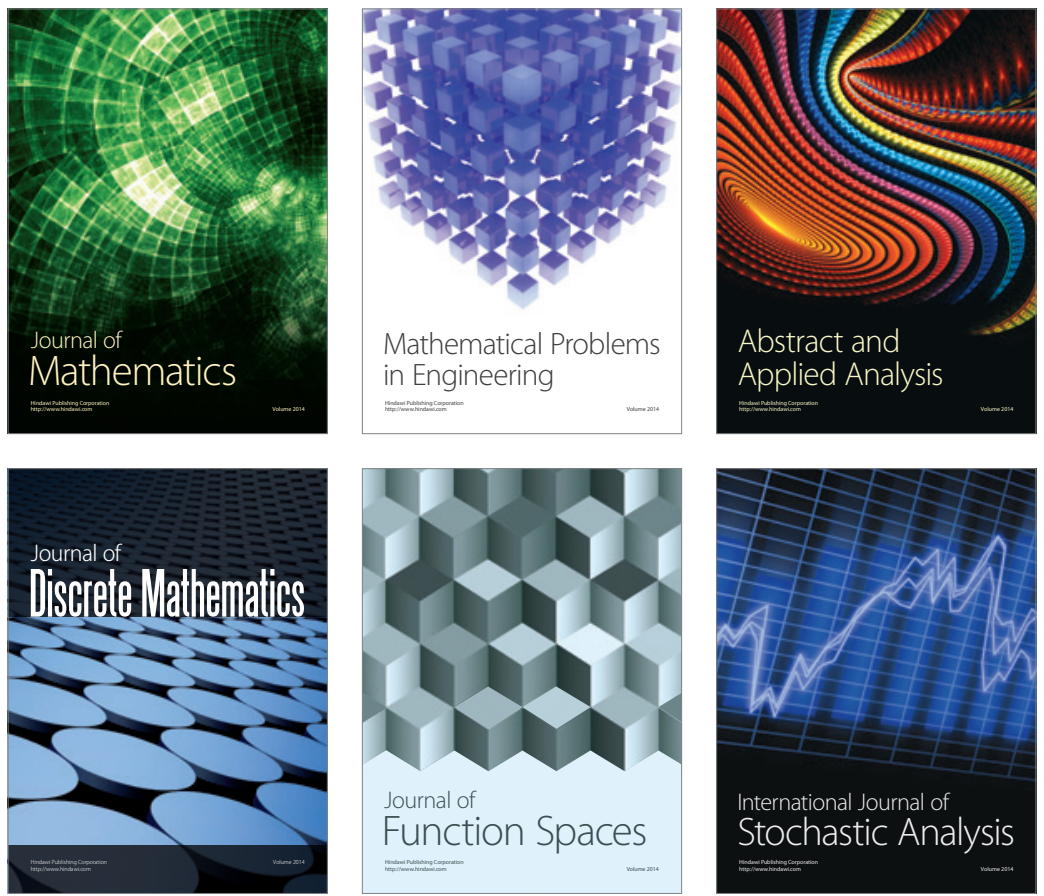

Journal of

Function Spaces

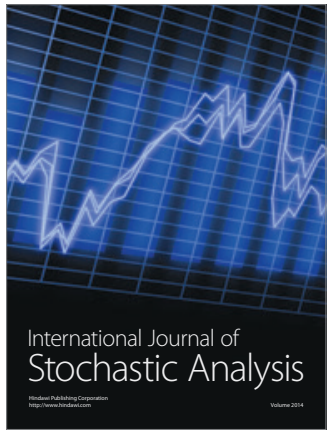

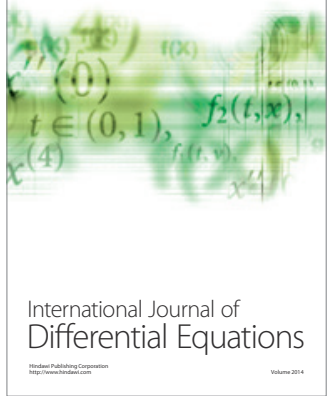
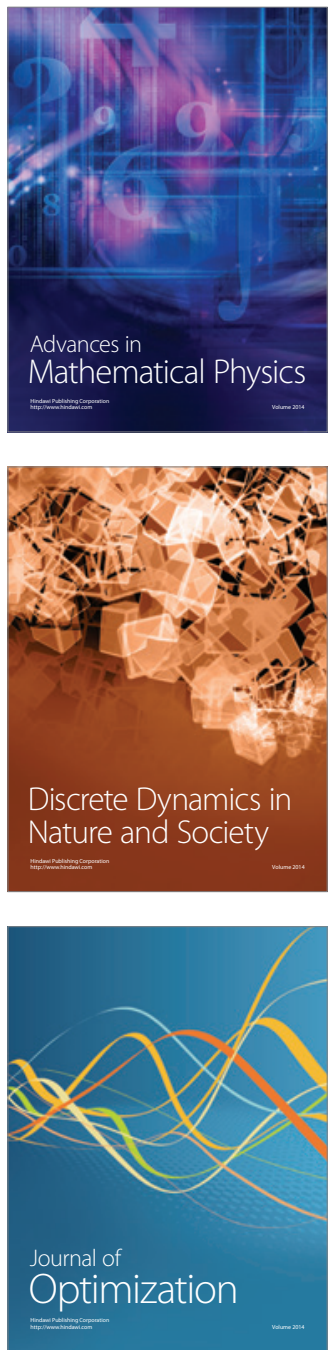